\title{
Polyketide Synthase Gene Expression in Relation to Chloromonilicin and Melanin Production in Monilinia fructicola
}

\author{
Fang-Yi Yu, ${ }^{1}$ Chiu-Min Chiu, ${ }^{1,7,8}$ Yue-Zhi Lee, ${ }^{2}$ Shiow-Ju Lee, ${ }^{2}$ Chien-Ming Chou, ${ }^{3}$ Bang-Jau You, ${ }^{4}$ Dai-Keng Hsieh, ${ }^{1,5}$ \\ Maw-Rong Lee, ${ }^{6}$ Miin-Huey Lee, ${ }^{1,5,8, \dagger}$ and Richard M. Bostock ${ }^{7,8, \dagger}$ \\ ${ }^{1}$ Department of Plant Pathology, National Chung Hsing University, Taiwan \\ ${ }^{2}$ Institute of Biotechnology and Pharmaceutical Research, National Health Research Institutes, Taiwan \\ ${ }^{3}$ Department of Plant Pathology, National Chung Hsing University, Taiwan (deceased 18 September 2017) \\ ${ }^{4}$ School of Chinese Pharmaceutical Sciences and Chinese Medicine Resources, China Medical University, Taichung, Taiwan \\ ${ }^{5}$ Advanced Plant Biotechnology Center, National Chung Hsing University, Taiwan \\ ${ }^{6}$ Department of Chemistry, National Chung Hsing University, Taiwan \\ ${ }^{7}$ Department of Plant Pathology, University of California, Davis, CA \\ ${ }^{8}$ NCHU-UCD Plant and Food Biotechnology Center, National Chung Hsing University, Taiwan \\ Accepted for publication 10 April 2020.
}

\begin{abstract}
Monilinia fructicola is a fungal pathogen of worldwide significance that causes brown rot of stone fruits. There are only few reports related to the production of biologically active polyketides by this pathogen. In this study, we examined an atypical M. fructicola strain TW5-4 that shows strong antimicrobial activity against various plant pathogens. TW5-4 also displays sparse growth in culture, low virulence, and higher levels of melanin compared with its albino mutant, TW5-4WM, and a wild-type strain Mf13-81. Antifungal compounds were extracted from TW5-4 and purified by thin-layer chromatography following visualization with an onthe-chromatogram inhibition assay. The principal antifungal compound was identified by linear ion trap mass spectrometry, high-resolution electro-spray ionization mass spectrometry, and proton nuclear mag-

a 10-member PKS gene family in the $M$. fructicola genome. Analyses of PKS gene expression found no strong correlation between chloromonilicin production in culture and transcript levels of any of the PKS gene family members in mycelium of strains TW5-4, TW5-4WM, and Mf1381. However, MfPKS12, a homolog of BcPKS12 involved in biosynthesis of 1,8-dihydroxynaphthalene (DHN)-melanin in Botrytis cinerea, was strongly expressed in mycelia of TW5-4 and Mf13-81. An MfPKS12silenced mutant accumulated significantly less melanin in mycelia, had lower resistance to polyethylene glycol-induced osmotic stress, and displayed reduced virulence on nectarine fruit. The results suggest that DHN-melanin is required for tolerance to osmotic stress and full virulence in $M$. fructicola.
\end{abstract} netic resonance analyses as the polyketide chloromonilicin. Multiple M. fructicola polyketide synthase (PKS) sequences were then cloned by degenerate PCR and inverse PCR. Sequence analyses support presence of
Keywords: biochemistry and cell biology, mycology, postharvest pathology and mycotoxins
Monilinia fructicola (G. Winter) Honey is a fungal plant pathogen of worldwide significance, affecting many members of the Rosaceae, and is especially damaging to stone fruits (Prunus spp.). M. fructicola causes brown rot blossom blight and fruit rot and is a necrotrophic pathogen related to members of the family Sclerotiniaceae, such as B. cinerea and Sclerotinia sclerotiorum with similar parasitic habits. Necrotrophs produce toxins and cell wall-degrading enzymes to kill host cells during infection and

†Corresponding authors: M.-H. Lee; mhlee@nchu.edu.tw, and R. M. Bostock; rmbostock@ucdavis.edu

First and second authors contributed equally to this work.

Funding: This work was supported by the NCHU-UCD Plant and Food Biotechnology Center, a cooperative training program between the National Chung Hsing University (Taiwan) and the University of California, Davis (U.S.A.), with funding provided by the Taiwan Ministry of Science and Technology (National Science Council; grant MOST 107-2313-B-005-032-MY3). This work was also supported in part by funds from the University of California Agricultural Experiment station to R. M. Bostock and by the Advanced Plant Biotechnology Center from The Featured Areas Research Center Program within the framework of the Higher Education Sprout Project by the Ministry of Education in Taiwan to M. H. Lee.

*The $e$-Xtra logo stands for "electronic extra" and indicates that supplementary figures and supplementary tables are published online.

The author(s) declare no conflict of interest.

C 2020 The American Phytopathological Society colonization (Laluk and Mengiste 2010; Pusztahelyi et al. 2016). There is strong evidence for a role of cell wall-degrading enzymes by $M$. fructicola in lesion development and pathogenesis (Chou et al. 2015; Lee et al. 2010). However, the contribution of low molecular weight toxins in brown rot disease is less clear (Byrde and Willetts 1977). Oxalic acid is an important phytotoxin produced by members of the family Sclerotiniaceae. However, gluconic acid appears to be the principal organic acid produced by $M$. fructicola, apparently contributing to host colonization through acidification of the infection court (De Cal et al. 2013). Malic, fumaric, and citric acids are also produced to a lesser degree, and fumaric acid has been shown to be a phytotoxin active in stone fruits (Mirocha et al. 1961). Plant pathogens also produce toxins to help exclude competitors for niche establishment. Production and turnover of such toxins would require tight regulation, and/or effective resistance mechanisms to avoid self-inhibition.

Polyketides are secondary metabolites in fungi important for survival (e.g., melanin), self-defense (e.g., antibiotics), and host attack (e.g., phytotoxins). Their structural complexity confer functional diversity and create many potential applications in pharmacology and biotechnology (Cox et al. 2018; Hussain et al. 2017). Polyketide synthases (PKS) are multifunctional enzymes that initiate polyketide biosynthesis via decarboxylative condensation between a thioesterified malonate derivative and an acyl thioester (Chan et al. 2009). PKS are grouped into three types based on their sequences, primary structures, and catalytic mechanisms (Cox and Simpson 2009). Type I PKS, found in bacteria, fungi, and plants, are large proteins (usually $>6 \mathrm{~kb}$ ) with multiple catalytic 
domains encoded by a single nucleotide sequence. Type II PKS are only found in bacteria and consist of multiple subunit proteins, each with a single catalytic role that coordinate polyketide synthesis. Type III PKS occur in bacteria, fungi, and plants and have a single catalytic function. In fungi, several Type III PKS have been characterized (Funa et al. 2007; Seshime et al. 2005, 2010a, b). However, Type I PKS are most common in fungi (Cox and Simpson 2009; Cox et al. 2018; Kroken et al. 2003).

The biosynthesis of polyketides by a Type I PKS begins with acetate or propionate, with subsequent additions of malonyl-CoA for polymer extension, a process catalyzed by functional domains in the protein that include ketoacyl synthase (KS), acyl transferase (AT), and acyl carrier protein (ACP) (Cox 2007). Nonreducing, partially reducing, and highly reducing PKSs all contain these three catalytic domains. Additional domains in partially and highly reducing PKSs may include ketoreductase (KR), dehydratase (DH), enoyl reductase (ER), and C-methyltransferase (CMeT) to further modify the polymer (Cox 2007). In the absence of an annotated genome sequence, fungal PKSs have been cloned by PCR with primers targeting conserved regions of $\mathrm{KS}, \mathrm{KR}$, and $\mathrm{CMeT}$ domains (Akamatsu et al. 2010; Amnuaykanjanasin et al. 2005; Bingle et al. 1999; Nicholson et al. 2001). PKSs typically have been found to comprise a large gene family in a fungal genome; members of Pezizomycotina, for example, carry up to $25 \mathrm{PKSs}$. Still, some fungi do not carry PKS genes in their genome, for instance some members in Saccharomycotina and Taphrinomycotina (Kroken et al. 2003).

Polyketides such as 1,8-dihydroxynaphthalene (DHN)-melanin polymers and various phytotoxins are important as pathogenicity and virulence factors (Pusztahelyi et al. 2016; Teichert and Nowrousian 2011). Fungal cell walls can contain melanin to protect cells from environmental stresses (Akamatsu et al. 2010; Kawamura et al. 1999; Moriwaki et al. 2004). Melanin also plays a critical role in modulating turgor during appressorium development and penetration into host tissue (Kawamura et al. 1997; Ryder and Talbot 2015; Takano et al. 1995). Classic examples of important polyketide phytotoxins include T-toxin (Baker et al. 2006), cercosporin (Choquer et al. 2005), and botcinic acid (Dalmais et al. 2011), among others.

We have collected many $M$. fructicola isolates from different peach orchards in Taiwan. One of the strains, TW5-4, grows slowly, forms dark colonies, and inhibits growth of other plant pathogens. The objective of this study was to further characterize this unusual strain. During the course of our study, we identified a major antifungal compound as a polyketide, which prompted cloning of PKS genes. Ten PKS were fully or partially cloned and sequenced. Gene expression analyses indicate that the 10 PKS genes are differentially expressed in mycelia, with one of these, MfPKS12, the most highly expressed. Functional characterization of MfPKS12 by gene silencing reveals that it contributes to DHN-melanin accumulation and virulence of $M$. fructicola.

\section{MATERIALS AND METHODS}

Fungal strains and cultivation. Fungal strains used in this study are listed in Supplementary Table S1. All strains were purified by single-spore isolation following culture from their original hosts or from peach orchard soils in Taiwan, except Mf13-81 (aka MUK1), which was isolated from infected peach fruit in a California (U.S.A.) orchard (Bostock et al. 1999). Single-spore isolates (TW51, TW5-2 and TW5-4) were obtained from isolate TW5 cultured from a mummified peach fruit in Li Mountain, Taiwan. All M. fructicola strains used in this study were verified with internal transcribed spacer (ITS) sequences. TW5-4WM was isolated after two serial single-spore isolations, originating from a spontaneous albino sector of strain TW5-4 growing on a potato dextrose agar (PDA) plate (Supplementary Fig. S1). Trichoderma-like fungi were isolated from soils of peach orchards in Taiwan and purified by single-spore isolation. They grew and sporulated rapidly on PDA, forming dark or light green colonies, with conidia produced from phialides on branched conidiophores. Determination as Trichoderma-like fungi was based on morphological characteristics, without further characterization to species. Fungal strains were maintained on V8 agar (16.3\% V8 juice, $0.08 \% \mathrm{CaCO}_{3}$, and $1.5 \%$ agar), potato sucrose agar (PSA; $20 \%$ potato extract, $2 \%$ sucrose, and $1.5 \%$ agar), or modified Sclerotinia minimal medium (Lee and Bostock 2006a). All fungal pathogens were cultured at 23 to $24^{\circ} \mathrm{C}$, except for Fusarium oxysporum f. sp. phaseoli, which was cultured at $28^{\circ} \mathrm{C}$.

Germination, appressorium formation, and sporulation. Conidia were collected from 7- to 9-day-old fungal cultures on V8 agar ( $M$. fructicola) or PSA ( $P$. digitatum and B. cinerea) and resuspended in $1 \mathrm{ml}$ of sterile water. Conidial suspensions were filtered through a Miracloth membrane (Cabiochem, U.S.A.) and adjusted to a desired concentration for further analysis. For germination and appressorium formation, $M$. fructicola conidial suspensions were washed twice as described previously (Lee and Bostock 2006b). Conidial suspensions containing $1 \mathrm{mM}$ sucrose were placed on a petri dish $\left(5 \mu \mathrm{l} / \mathrm{drop} ; 1 \times 10^{5}\right.$ spores $\left./ \mathrm{ml}\right)$, and germination and appressorium formation were observed $6 \mathrm{~h}$ postincubation under a light microscope. For sporulation, $M$. fructicola strains were cultured on V8 agar, and conidia were collected from each plate at 7 days postincubation and quantified using a hemocytometer.

Melanin quantitation. Melanin was quantified with slight modification of the protocol described by Babitskaya et al. (2000). Briefly, fungal strains were cultured atop cellophane membranes on V8 agar or PDA plates in the dark. Mycelia $(100 \mathrm{mg})$ were collected from the membranes into tubes containing $0.5 \mathrm{~N} \mathrm{NaOH}$, and the tubes were placed in a $100^{\circ} \mathrm{C}$ water bath for $2 \mathrm{~h}$. The supernatant was collected by centrifugation at $12,000 \mathrm{rpm}$ for $10 \mathrm{~min}$, and the $\mathrm{pH}$ was adjusted with $\mathrm{HCl}$ to 2.0 to precipitate melanin. The melanin pellets were collected by centrifugation at $12,000 \mathrm{rpm}$ for 15 min. Melanin was resuspended in $0.5 \mathrm{~N} \mathrm{NaOH}$ and measured with a spectrophotometer at $459 \mathrm{~nm}$.

Disease assay. Rose petals (Rosa 'Flaming Peace'), peach (Prunus persica 'Tian Tao'), and nectarine ( $P$. persica 'Fantasy') fruits were used to assess pathogenicity and virulence as described previously (Chiu et al. 2013; Yu et al. 2017). Lesion size was calculated by Spot image analysis (Spot RT Software version 4.6; Diagnostic Instruments, Inc., U.S.A.). Six rose petals and 5 to 10 fruits were used for one paired inoculation in each experiment. Two separate experiments were performed for the inoculation on each plant species.

Antimicrobial activity assay. To assess antagonism of different $M$. fructicola isolates against $B$. cinerea and $P$. digitatum, a mycelial agar disc $(6 \mathrm{~mm})$ of the target pathogen was placed at the center of a PSA plate and four mycelial agar discs $(6 \mathrm{~mm})$ of a $M$. fructicola isolate were each placed at four opposite positions at $2 \mathrm{~cm}$ distance from a target mycelial disc. In dual cultures, an $M$. fructicola isolate and target pathogen were placed $4 \mathrm{~cm}$ opposite each other on a PSA plate. In this assay, mycelial discs of $M$. fructicola isolates were from 8-day-old PSA cultures, while mycelial discs of the target pathogen were from 4-day-old PSA cultures. The plates were incubated at $24^{\circ} \mathrm{C}$ for 4 or 6 days. The clear zone formed between target pathogen and $M$. fructicola isolate was measured.

In a second assay format, $100 \mu$ l of spore suspension $\left(2 \times 10^{5}\right.$ spores $/ \mathrm{ml}$ ) of target pathogen was sprayed on a PSA plate followed by placement of a mycelia-cellophane strip of $M$. fructicola (see below) at the center of the plate. Plates were incubated at $24^{\circ} \mathrm{C}$ for 4 to 6 days, and the zone of clearing surrounding the strip was measured. Using this same format, we tested mycelial extracts (see below) for antimicrobial activity by spraying a spore suspension of the target pathogen on a PSA plate followed by placement of a filter paper disc ( $8 \mathrm{~mm}$; Advantec, Japan) containing $40 \mu \mathrm{l}$ of extract on the plate. Zones of clearing around each paper disk were measured after incubation at $24^{\circ} \mathrm{C}$ for 4 to 6 days. 
Antimicrobial compound extraction. Monilinia fructicola isolate TW5-4 was cultured on PSA plates topped with cellophane for various incubation periods. Mycelia-cellophane strips $(1 \times 5 \mathrm{~cm})$ were excised to assay for antimicrobial activity as described above. Mycelia also were collected from the cellophane and ground to a powder, and immersed overnight in $50 \mu \mathrm{l}$ of ethyl acetate (EA) per $\mathrm{cm}^{2}$ of cellophane-mycelial mat. Insoluble material was then removed by centrifugation at $10,000 \mathrm{rpm}$ for $5 \mathrm{~min}$. The crude extracts were tested for antimicrobial activity on PSA plates. To isolate the antimicrobial compound(s), TW5-4 mycelia cultured on PSA for 10 days were collected and extracted three times with EA. The three EA extracts were combined and thoroughly mixed with an equal volume of deionized water, and the phases allowed to separate at $4^{\circ} \mathrm{C}$ overnight. The water and EA phases were collected separately and concentrated by freeze drying (FDU-1100, Eyela, Japan) or by a rotary evaporator (Vac V-500 [Switzerland] with Waterbath B-480, Rotavapor R240 and Vacuum controller B-721), respectively. The dried concentrates were weighed and then dissolved in DMSO or EA for bioactivity assays, or in EA for thin-layer chromatography (TLC) analysis.

Inhibitory activity of mycelial extracts on spore germination and growth. For spore germination inhibition of target pathogens, mycelial extracts were dissolved in DMSO and mixed with PDB (Difco) and spores (in water) to make a final suspension containing $2 \times 10^{5}$ spores $/ \mathrm{ml}$ in 1/4-strength PDB and $0.1 \%$ DMSO. Ten microliters of the suspension was placed on a glass slide and incubated in a moist chamber at $25^{\circ} \mathrm{C}$. Spore germination was determined after a $16 \mathrm{~h}$ incubation. Spores suspended in 1/4strength PDB and $0.1 \%$ DMSO served as a control.

To assess growth inhibition of target pathogens, $100 \mu \mathrm{l}$ of spore suspension $\left(2 \times 10^{5}\right.$ spores $\left./ \mathrm{ml}\right)$ was sprayed on a PSA plate and an 8$\mathrm{mm}$ filter disk containing $80 \mu \mathrm{l}$ of EA extract was placed on the PSA plate and incubated at $25^{\circ} \mathrm{C}$ for 2 days. Growth of target pathogens on PSA plates containing filter disks to which $80 \mu \mathrm{l}$ of EA solvent had been added served as a control. In both treatments, the EA solvent was allowed to evaporate from the disk prior to placement on the PSA plates.

TLC, HPLC, and liquid chromatography tanden mass spectrometry analyses. The EA extract of $M$. fructicola isolate TW5-4 was analyzed by TLC (Silica gel, $60 \mathrm{~F}_{254}$, Merck, Germany) with a developing solvent EA, hexane, and methanol (0.192:0.769: 0.038; vol/vol/vol). The developed TLC plates were examined under UV $(254 \mathrm{~nm})$ or near-UV light $(365 \mathrm{~nm})$. For detection of phenolic compounds, plates were sprayed with a solution containing $2 \% \mathrm{FeCl}_{3}$ in $100 \%$ ethanol (Exarchou et al. 2002). To identify antimicrobial compounds, an on-the-chromatogram inhibition assay (OCIA) was performed as follows. A developed TLC plate was top-layered with $1 \mathrm{ml}$ of semisolid PSA-spore suspension containing $100 \mu \mathrm{l}$ of spore suspension $\left(2 \times 10^{5} \mathrm{spores} / \mathrm{ml}\right)$ of target pathogen and $0.9 \mathrm{ml}$ of PSA in which agar content was adjusted to $0.7 \%$. After incubation at $24^{\circ} \mathrm{C}$ for 2 days, the plate was stained with lactophenol cotton blue solution $(0.05 \mathrm{~g}$ of cotton blue, $20 \mathrm{ml}$ of water, $20 \mathrm{~g}$ of phenol crystals, and $40 \mathrm{ml}$ of glycerol). The silica gel subtending a clear zone indicating an area of antimicrobial activity was scraped from the plate and dissolved in EA or acetonitrile. Silica gel powder was removed by filtration through a nylon membrane. When dissolved in EA, usually less than $100 \mu \mathrm{l}$, the EA was removed in a dry bath in a fume hood and then resuspended in the same volume of DMSO for phytotoxicity assays. The acetonitrile solution was analyzed by using a LTQ XL linear ion trap mass spectrometer (Thermo Scientific) with electrospray ionization in positive-ion detection mode to identify the active compound. The dry EA extract of $54 \mathrm{mg}$, prepared from a collection of 440 PSA culture plates of TW5-4, was resolved, fractioned, and purified by silica gel column chromatography $(1 \times 25 \mathrm{~cm}, 70$ to 230 mesh, ASTM; Merck Co.) in a benzene/EA (80:1) solvent system. The target fractions were collected and evaporated to yield chloromonilicin $(8.2 \mathrm{mg})$, which was identified and verified by high-resolution electro-spray ionization mass spectrometry (HRESIMS) and nuclear magnetic resonance (NMR) analyses.

Phytotoxicity assay. The EA extracts dissolved in DMSO were diluted with sterile water to bring the final DMSO concentration to $0.5 \%$. The diluted DMSO-EA extracts were applied ( $5 \mu \mathrm{l}$ per drop) to unwounded and needle-wounded petals and $0.5 \%$ DMSO solution was used as control. The petals were incubated in a moist chamber at $25^{\circ} \mathrm{C}$.

Fungal nucleic acid extraction. $M$. fructicola Mf13-81 was cultured on cellophane-topped V8 agar plates $(9 \mathrm{~cm})$ at $23^{\circ} \mathrm{C}$ for 7 days in the dark. An appropriate amount of hyphae was scraped into a $1.5-\mathrm{ml}$ microcentrifuge tube for genomic DNA extraction, as described previously (Lee et al. 2010). For RNA extraction, fungal strains were cultured on cellophane-topped V8 agar plates $(9 \mathrm{~cm})$ at $23^{\circ} \mathrm{C}$ for 6 days in the dark. Hyphae were scraped from the cellophane and RNA was extracted as described previously (Lee et al. 2010).

PKS gene cloning by degenerate PCR and inverse PCR. Partial sequences of polyketide synthase (PKS) genes were cloned by degenerate PCR and genomic DNA of $M$. fructicola Mf13-81 was used as template. Five sets of degenerate primers were designed to correspond to the conserved regions of the $\beta$-ketoacyl synthase domain (LC1/LC2c, LC3/LC5c) (Bingle et al. 1999), the Cmethyltransferase domain (CMeT1/CMeT 3c) (Nicholson et al. 2001), the $\beta$-ketoacyl synthase domain (KAF1/KAR1), and the acyltransferase domain (KAF1/KAR2) (Amnuaykanjanasin et al. 2005). The primer sequences are listed in Supplementary Table S2. PCR conditions were set as follows: an initial reaction at $94^{\circ} \mathrm{C}$ for $2 \mathrm{~min}, 34$ cycles of $94^{\circ} \mathrm{C}$ for $30 \mathrm{~s}, 60^{\circ} \mathrm{C}$ (varied temperature depending on primers used) for $40 \mathrm{~s}$, and $72^{\circ} \mathrm{C}$ for $1 \mathrm{~min}$, followed by an additional $5 \mathrm{~min}$ extension at $72^{\circ} \mathrm{C}$. Amplified products were ligated to the pGEM-Teasy vector (Promega, Madison, U.S.A.) and then transferred into Escherichia coli XL-1 blue (Stratagene, U.S.A.). Plasmids were isolated and the inserted fragments were sequenced. Approximately 300 to 900 bp sequences were obtained and the flanking sequences were further cloned by inverse PCR (Lee et al. 2010). Briefly, genomic DNA of Mf13-81 was digested with restriction enzymes EcoRI, EcoRV, XhoI, or HindIII, and then selfligated by DNA ligase. After treatment with a PCR cleanup kit, the ligation mixture was diluted for PCR reaction with primers designed from the known sequence to amplify the flanking regions. If necessary, nested PCR was conducted. The PCR products were sequenced and assembled. The 10 sequences were submitted to GenBank (accession number MfPKS-LC1, MT095080; MfPKS12, MT095081; MfPKS-LC3, MT095082; MfPKS-LC4, MT095083; MfPKS-LC5, MT095084; MfPKS-KAF1, MT095085; MfPKSKAF2, MT095086; MfPKS-KAF3, MT095087; MfPKS-KAF4, MT095088; and MfPKS-KAF5, MT095089).

Semiquantitative reverse transcription PCR (sq-RTPCR). Fungal RNA was treated with DNase I and converted to cDNA by MMLV High Performance Reverse transcription (Epicentre, Wisconsin, U.S.A.) using Oligo-dT (5'-(T)25VN-3') as primer (Lee et al. 2010). sq-RT-PCR was conducted as described previously (Lee et al. 2010). Briefly, PCR reactions were performed in a total 50- $\mu 1$ reaction mixture, with TUB2 used as a control to calculate the relative expression. All primers used in this assay are listed in Supplementary Table S3. The PCR program was set as follows: an initial reaction at $95^{\circ} \mathrm{C}$ for $2 \mathrm{~min}, 34$ cycles of $94^{\circ} \mathrm{C}$ for $30 \mathrm{~s}, 60^{\circ} \mathrm{C}$ for $40 \mathrm{~s}$, and $72^{\circ} \mathrm{C}$ for $40 \mathrm{~s}$, followed by an additional 5 min extension at $72^{\circ} \mathrm{C}$. PCR reaction mixtures were collected after $20,25,30$, and 35 cycles, $7 \mu$ per collection, and were visualized by electrophoresis using $1.2 \%$ agarose gel and staining with ethidium bromide. The band density was determined by Kodak ID Image Analysis Software. The PCR product amplified within the exponential stage was used to calculate band density ratios of PKS genes relative to the $\beta$-tubulin gene ( $t u b 2)$.

Bioinformatic analysis. The PKS sequences obtained were analyzed with the BLAST program of the National Center for 
Biotechnology Information (NCBI) Spot RT Software version 4.6 (Diagnostic Instruments Inc., U.S.A.) to search the database for similar sequences. Protein function domain predictions were analyzed with InterProscan. The phylogenetic analysis was performed by CLUSTALW 1.18 (http://workbench.sdsc.edu/) of SDSC Biology Workbench 3.2 based on the highly-retained region C/DPxxR to ExHGHG within the sequence of the KS domain (approximately 222 to 233 amino acids).

Gene silencing and identification of silenced strains. Gene silencing vector pSilent-Dual1, kindly provided by Dr. Nakayashiki (Kobe University, Kobe, Japan) (Nguyen et al. 2008), was used to generate the MfPKS12 silencing construct. Briefly, a 533-bp MfPKS12 open reading frame (ORF) fragment was amplified using the primer pair LC2-6-B and LC2-6-R1 (Supplementary Table S3) and cloned into pSilent-Dual1. The MfPKS12 silencing vector was transferred to M. fructicola $\mathrm{Mf13}-81$ by $\mathrm{CaCl}_{2} /$ PEG-mediated protoplast transformation as described previously (Chou et al. 2015; Lee et al. 2010). Putative transformants were screened by PCR for presence of the hptII gene, and five transformants carrying the silencing construct were used for further
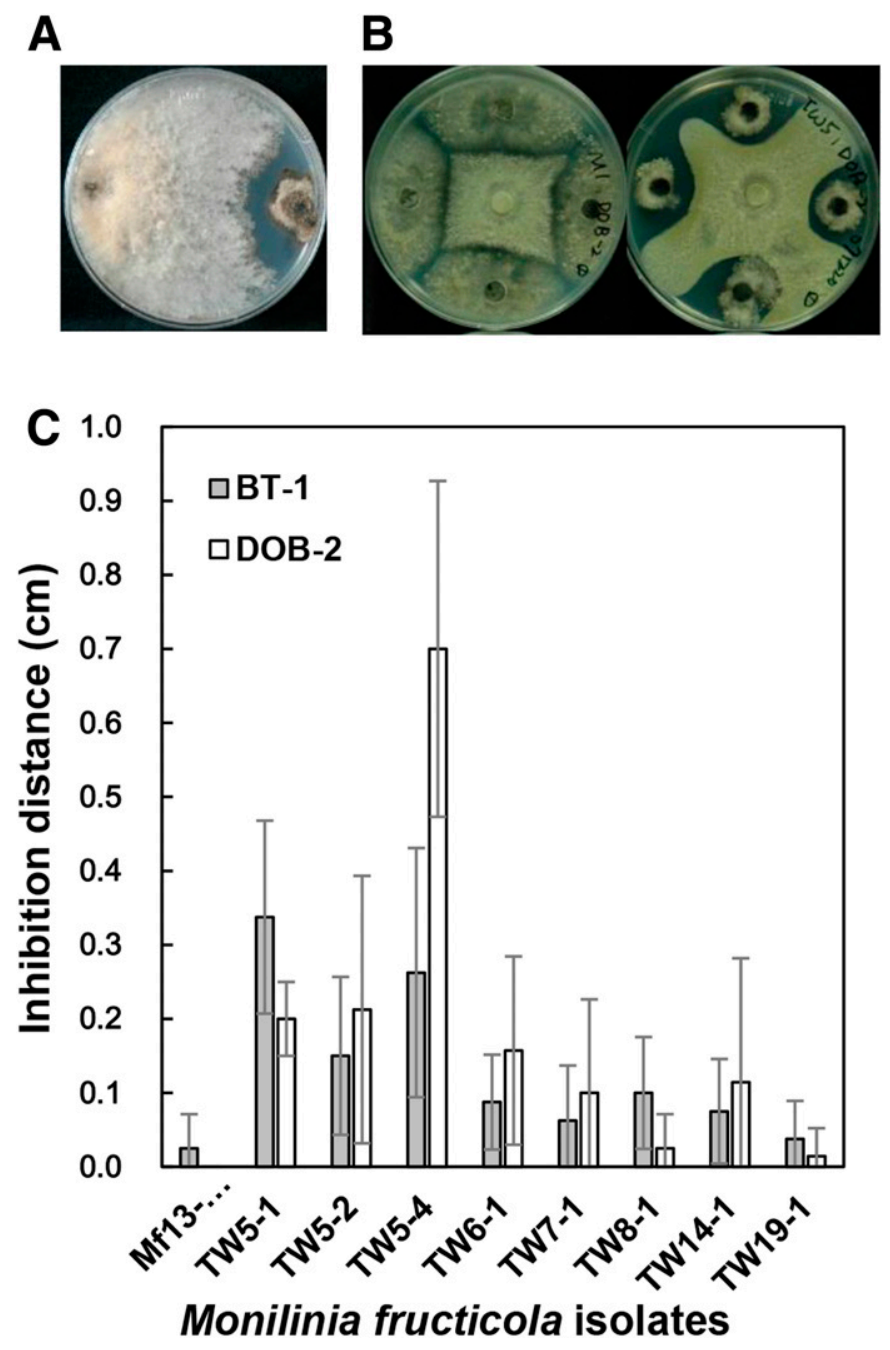

Fig. 1. Antagonism of Monilinia fructicola isolates to Botrytis cinerea strain BT-1 and Penicillium digitatum strain DOB-2. A, Dual culture of $M$. fructicola isolate TW5-4 (right) showing zone of inhibition against isolate Mf13-81 (left), 10 days postinoculation. B, Coculture of $M$. fructicola isolate Mf13-81 (left) or TW5-4 (right) to DOB-2, 6 days postinoculation, in which DOB-2 was inoculated at the center and surrounded with four mycelial plugs of TW5-4 or Mf13-81. C, Antagonism of various M. fructicola isolates to BT-1 and DOB-2. Zones of inhibition were measured as the average distance between the colony edges of an $M$. fructicola isolate and the target fungus, 6 days postinoculation. analysis, including gene expression and phenotyping. To identify MfPKS12 gene-silenced strains, transformants were cultured on PDA and V8 medium covered with one layer of cellophane. RNA was isolated from mycelia collected from 6-day-old cultures by using Qiagen RNeasy kit and treated with DNaseI to remove DNA. The RNA was then transferred to cDNA by the iScript cDNA synthesis kit (Bio-Rad Lab, Inc.). Relative expression level of MfPKS12 was detected by quantitative RT-PCR (qRT-PCR) with the Bio-Rad Fast SYBR Green kit using an Applied Biosystems 7500 Fast Real-Time PCR System (Applied Biosystems, Inc). The tub2 gene of $M$. fructicola was used as internal control to calculate the relative expression level as described previously (Chou et al. 2015).

Functional characterization of $M f P K S 12$-silenced strains. Fruits (mature, stage III) of nectarine and peach were used to assay strains for virulence. Five microliters of conidial suspension (100 conidia/ $\mu \mathrm{l})$ of wild-type (WT) and MFPKS12-silenced transformants was inoculated on the same fruit with the WT strain on the left side and a transformant on the right side. Lesion size was calculated as described above. To assess strains for tolerance to hypertonic solutions, $10 \mu \mathrm{l}$ of spore suspension $\left(1 \times 10^{5}\right.$ spores $\left./ \mathrm{ml}\right)$ of WT and MFPKS12-silenced transformants was placed in a petri dish and incubated in the dark at $25^{\circ} \mathrm{C}$ for $12 \mathrm{~h}$. The liquid was removed with a piece of filter paper and a 10- $\mu$ l PEG8000 solution (chilled to $20^{\circ} \mathrm{C}$ ) was applied to the spores. Morphology of fungal structures was observed under a light microscope after $10 \mathrm{~min}$.

Analysis of experimental data. Experiments were conducted at least twice with at least three replicates of each treatment within each experiment, except as noted otherwise. Means comparisons in disease assays were determined by using paired $t$ test $(P \leq 0.05)$. The significance of differences among treatments in other experiments was determined by analysis of variance and means separation by Tukey's analysis $(P \leq 0.05)$ using Statistical Package for the Social Sciences software, version 20 (IBM SPSS software).

\section{RESULTS}

M. fructicola isolates inhibit growth of other fungi. In a screen to select Trichoderma-like fungi as potential antagonists of M. fructicola, we found that M. fructicola produces metabolites into the medium that inhibit the growth of other fungi, including Botrytis cinerea and Penicillium digitatum (Fig. 1, Supplementary Fig. S1). An atypical, darkly pigmented isolate, TW5-4, confirmed to be M. fructicola by ITS sequence, exhibited strongest suppression of growth of multiple fungal pathogens (Fig. 1, Table 1), including M. fructicola WT isolate Mf13-81 (Fig. 1A). TW5-4 was isolated from a diseased peach fruit from an orchard located at high elevation. The diseased fruit was partially mummified, while a portion of the fruit remained healthy, suggesting that TW5-4 colonization had ceased or was suppressed. TW5-4 and an albino mutant, TW5-4WM, purified from a colony sector of TW5-4, were further characterized and compared with our extensively studied WT Mf13-81 (aka MUK-1) isolate (Chiu et al. 2013; Chou et al. 2015; Lee and Bostock 2006a, b, 2007; Lee et al. 2010; Yu et al. 2017).

Growth, morphology, and pathogenicity of TW5-4. Growth and colony morphology of the three $M$. fructicola isolates were remarkably different on PDA and V8 agar media. Mf13-81 produces light brown aerial hyphae, while TW5-4WM forms a pale white colony. However, TW5-4 displayed extremely slow growth and produced dark colonies (Supplementary Fig. S2) and fewer conidia, and had lower germination and appressorium formation rates than the other two isolates (Table 2). Disease assays revealed that TW5-4 produced few or no lesions on rose petals and on peach and apple fruits (Supplementary Fig. S3 and data not shown). TW54 accumulated significantly higher amounts of melanin than 
Mf13-81 and TW5-4WM at 6 days postinoculation (Supplementary Fig. S4).

Antimicrobial activity of $\boldsymbol{M}$. fructicola isolates. To further characterize the observed antimicrobial activity, TW5-4, Mf13-81, and TW5-4WM were individually cultured on a cellophane membrane placed atop PSA medium. After different culture periods, the mycelia-cellophane strip was used to assay antibiotic activity against $P$. digitatum, and results showed that 6- to 12-dayold cultures of TW5-4 inhibited $P$. digitatum colony development (data not shown). Cellophane membrane/agar cultures of Mf13-81 and TW5-4WM were only weakly antagonistic to $P$. digitatum. Therefore, antibiotic compounds were extracted by EA from mycelia of cellophane/agar cultures. EA extracts of TW5-4 mycelia collected from 6-day-old cellophane/agar cultures had detectable antimicrobial activity against $P$. digitatum that increased to a maximum in 10-day-old cultures (Fig. 2A and B). EA extracts of Mf13-81 and TW5-4WM mycelia collected from 4- to 12-day-old cultures had no obviously detectable antimicrobial activity against $P$. digitatum (Fig. 2A). B. cinerea was less sensitive than $P$. digitatum to TW5-4 EA extracts (Fig. 2B). The TW5-4 EA extracts also inhibited spore germination of $P$. digitatum, with extract from 10-day-old cultures causing more than $70 \%$ inhibition at $0.5 \mathrm{ppm}$ (based on dry weight of the crude extract) and $100 \%$ inhibition at 5 ppm (Fig. 2C). Spore germination of B. cinerea was not inhibited by $50 \mathrm{ppm}$ of the EA extract, but was completely inhibited by $100 \mathrm{ppm}$ of the EA extract (data not shown). TW5-4 mycelia cultured for 10 to 12 days were collected for antimicrobial compound purification.

Antimicrobial compound purification. Compounds in EA extracts were separated by TLC and examined with UV light at 254 and $365 \mathrm{~nm}$. To detect antimicrobial compounds on the TLC plate, OCIA was conducted as described in the Materials and Methods. As shown in Figure 3, the antimicrobial activity localizes to a position with $\operatorname{Rf} 0.28$ when separated with EA/hexane (1:4; vol/vol), or at Rf 0.45 when separated with EA/hexane/methanol (0.192:0.769:

TABLE 1. The antagonistic activity of Monilinia fructicola strain TW5-4 to various fungal pathogens

\begin{tabular}{llc}
\hline Fungal species & Strain & $\begin{array}{c}\text { Radius of inhibition } \\
\text { zone }(\mathrm{mm})\end{array}$ \\
\hline Alternaria solani & AS01 & No inhibition \\
Botrytis cinerea & $\mathrm{Bt} 10$ & $6.5 \pm 0.5$ \\
Colletotrichum acutatum & Coll-153 & No inhibition \\
Colletotrichum capsici & 470 & No inhibition \\
Colletotrichum higginsianum & BC04 & $6.0 \pm 0.6$ \\
Colletotrichum gloeosporioides & Gou11 & No inhibition \\
Colletotrichum gloeosporioides & CO-1 & $2.7 \pm 0.9$ \\
Fusarium oxysporum f. sp. phaseoli & CYC & No inhibition \\
Magnaporthe grisea & 186 & $2.6 \pm 0.57$ \\
Penicillium digitatum & DOB-2 & $8.0 \pm 2.0$ \\
Rhizoctonia solani & RN-1 & $2.7 \pm 0.4$ \\
Sclerotium rolfsii & JWH & No inhibition \\
\hline
\end{tabular}

TABLE 2. Sporulation, germination and appressorium formation of three Monilinia fructicola strains

\begin{tabular}{lccc}
\hline Strain & Sporulation $\left(\times 10^{5}\right)^{\mathrm{a}}$ & Germination $(\%)^{\mathrm{b}}$ & $\begin{array}{c}\text { Appressoria } \\
\text { formation }(\%)^{\mathrm{b}}\end{array}$ \\
\hline Mf13-81 & $96.6 \pm 3.4^{\mathrm{c}}$ & $96.1 \pm 0.1$ & $82.5 \pm 5.1$ \\
TW5-4 & $0.6 \pm 0.1$ & $75.9 \pm 5.5$ & $16.2 \pm 3.1$ \\
TW5-4WM & $65.3 \pm 0.01$ & $94.0 \pm 0.1$ & $73.5 \pm 5.5$ \\
\hline
\end{tabular}

a Spores were collected from each strain cultured on a 9-cm V8 agar plate 7 days after inoculation.

b Spore germination and appressoria formation were measured by placing 500 spores in water containing $1 \mathrm{mM}$ sucrose on a petri dish after $6 \mathrm{~h}$ incubation at room temperature.

c Means and standard errors of three replicates are presented.
0.038; vol/vol/vol). Phenolic compounds, detected with $\mathrm{FeCl}_{3}$ reagent, comigrated to the same position with antimicrobial activity (Fig. 3). The antimicrobial compounds were separated and recovered from the TLC plate and analyzed with LTQ XL mass spectrometry. Under positive charge conditions, two dominant peaks were detected with $[\mathrm{M}+\mathrm{H}]$ at 347 and 351 , indicating the two compounds have molecular weights of 346 and 350, respectively (Supplementary Fig. S5).

The two compounds were consistent with chloromonilicin and its methanolysis product (II), as reported previously (Sassa et al. 1989), since the TLC solvent contained methanol. To prevent methanolysis during further compound purification, a solvent system of benzene/EA was used to reconstitute the dry crude EA extract and in the following chromatographic fractioning and purification. Target fractions were collected to afford chloromonilicin, which was further identified and verified with HRESIMS and ${ }^{1} \mathrm{H}$ NMR analyses (Fig. 4). The two major peaks of M.W. 351 $[\mathrm{M}+\mathrm{H}]$ and $373[\mathrm{M}+\mathrm{Na}]$ in the HRESIMS were assigned to chloromonilicin while no obvious M.W. peaks, $347[\mathrm{M}+\mathrm{H}]$ or 369 $[\mathrm{M}+\mathrm{Na}]$, were detected for the proposed methanolysis product observed in the original TLC separation. The obtained NMR assignment was as follows. Chloromonilicin: ${ }^{1} \mathrm{H} \mathrm{NMR}(400 \mathrm{MHz}$, $\left.\mathrm{CDCl}_{3}\right): 2.46(\mathrm{~s}, 3 \mathrm{H}), 3.83(\mathrm{~s}, 3 \mathrm{H}), 6.45(\mathrm{~s}, 1 \mathrm{H}), 6.76(\mathrm{~d}, \mathrm{~J}=0.8 \mathrm{~Hz}$, $1 \mathrm{H}), 6.87(\mathrm{~d}, \mathrm{~J}=0.8 \mathrm{~Hz}, 1 \mathrm{H}), 6.90(\mathrm{~s}, 1 \mathrm{H}), 11.70(\mathrm{~s}, 1 \mathrm{H})$, and MS (ESI) $\mathrm{m} / \mathrm{z} 373(\mathrm{M}+\mathrm{Na})^{+}$.

Phytotoxic activity of TW5-4 mycelial extracts. To assess the potential toxicity of TW5-4 extracts on host plants, antimicrobial compounds isolated by TLC-OCIA were applied to intact and wounded rose petals. When treated with $40 \mu \mathrm{g}$ per 5 - $\mu$ l drop,
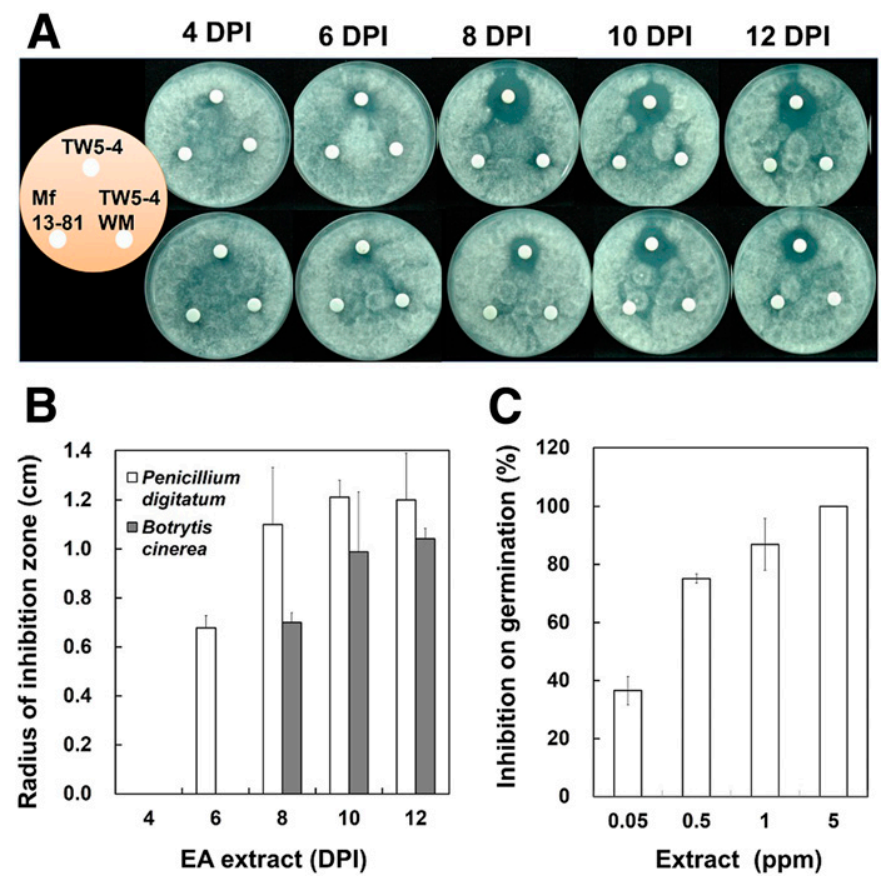

Fig. 2. The effect of culture age on antimicrobial activity of Monilinia fructicola strains Mf13-81, TW5-4, and TW5-4WM. A, Antimicrobial activity against Penicillium digitatum of ethyl acetate (EA) extracts of mycelia of $M$. fructicola strains Mf13-81, TW5-4, and TW5-4WM collected 4, 6, 8, 10, and 12 days postinoculation (DPI) on potato sucrose agar (PSA). Eighty microliters of EA extract from $1.6 \mathrm{~cm}^{2}$ of cellophane-mycelial mat of each strain was applied to a filter paper disc in the pattern shown to assess antibiotic activity against $P$. digitatum. B, Antimicrobial activity against $P$. digitatum and $B O-$ trytis cinerea of EA extracts of TW5-4 mycelia collected 4, 6, 8, 10, and 12 days postinoculation (DPI) on PSA. Cellophane-mycelial mats were extracted with $50 \mu \mathrm{l}$ of $\mathrm{EA} / \mathrm{cm}^{2}$, and $80 \mu \mathrm{l}$ of the crude extract was applied to the filter paper disc for the assay. $\mathbf{C}$, Inhibition of spore germination of $P$. digitatum by EA extract of TW5-4 mycelia from a 10-day culture on PSA. Concentrations are based on the dry weight of the crude extract. 
wounded petals developed necrotic lesions within $24 \mathrm{~h}$, while no significant damage was observed on the control treatment (Supplementary Fig. S6). Necrotic lesions had not expanded beyond the site of application at $48 \mathrm{~h}$.

PKS gene cloning and phylogenetic analysis. Production of chloromonilicin, a polyketide, should require a PKS. To better understand regulation of chloromonilicin biosynthesis, PKS genes were amplified from genomic DNA of $M$. fructicola Mf13-81 using degenerate PCR. Twelve PKS partial sequences were cloned, and flanking regions of some of the partial sequences were further identified by inverse PCR. After sequence assembly, 10 gene fragments were obtained and named $L C 1, L C 2, L C 3, L C 4, L C 5$, $K A F 1, K A F 2, K A F 3, K A F 4$, and $K A F 5$ (Supplementary Table S4). Nucleotide sequence query of these fragments in the NCBI database by blastx revealed best hits ranging from 63 to $95 \%$ identity to known PKS genes (Supplementary Table S5). The full-length $(6,690 \mathrm{bps})$ ORF of LC2 contains five introns with sizes 48 to $59 \mathrm{bps}$ and encodes a protein with 2,144 amino acids (Supplementary Table S4). The functional domains of LC2 were predicted with InterProScan.

LC2 is a nonreducing PKS containing the starter unit ACP (acylcarrier protein) transacylase (SAT), beta-ketoacyl synthase (KS), acyl transferase (AT), polyketide product template (PT), phosphopantetheine-binding (P), and thioesterase (TE) domains (Supplementary Fig. S7). Amino acid sequence determination using blastp shows that LC2 is highly similar to BcPKS12 in Botrytis and Sclerotinia species, with over $87 \%$ identity and $100 \%$ coverage (Supplementary Fig. S7). Both LC2 and BcPKS12 appear to have the same functional domain arrangement (Supplementary Fig. S7). Therefore, LC2 was designated MfPKS12. The complete ketoacyl transferase domain (DxxFF to ExHGTG; KS) was obtained from seven (LC1, LC2, LC3, LC4, LC5, KAF2, and KAF4) PKS genes. Based on amino acid sequences of the KS domains, phylogenetic relationships of seven PKSs and PKSs from other fungi were compared. These comparisons reveal that LC1 and LC2 are closely related to PKSs involved in melanin biosynthesis, while LC3, LC4, and KAF2 are associated with production of toxins (Supplementary Fig. S8).

PKS gene expression. To analyze expression of the 10 PKS genes in the three $M$. fructicola strains, the three strains were cultured on cellophane disks atop V8 agar for 6 days. RNA was extracted from the mycelia and gene expression assessed by sq-RT-
PCR. Mf13-81 and TW5-4 expressed higher levels of $L C 1$ and $L C 2$ (MFPKS12) than TW5-4WM, while TW5-4 expressed slightly higher levels of $L C 5$ and $K A F 3$ than Mf13-81 and TW5-4WM (Fig. 5). These results suggest that LC5 and KAF3 are associated with chloromonilicin production.

Functional characterization of MfPKS12 by gene silencing. To begin to identify PKS genes involved in production of chloromonilicin and other polyketides in M. fructicola, we attempted to overexpress or knockout PKS genes in TW5-4WM and TW5-4. However, DNA transformation in these strains either by Agrobacterium tumefaciens-mediated transformation or by protoplast/PEG-mediated transformation was unsuccessful. Although Mf13-81 (WT) does not display obvious antibiotic activity, we selected it for functional studies because of its well-established transformation system (Chiu et al. 2013; Chou et al. 2015; Lee and Bostock 2006a, b, 2007; Lee et al. 2010; Yu et al. 2017). In our experience, gene disruption by homologous replacement in multinucleate $M$. fructicola results in incomplete or partial phenotypes for the target of interest (Lee and Bostock 2006a; Chou et al. 2015; Yu et al. 2017). However, gene knockdown by silencing in Mf13-81 was performed successfully in a previous study (Yu et al. 2017). We selected the $L C 2$ (MfPKS12) gene for targeting in functional studies because we obtained a complete ORF and it was expressed at relatively higher levels compared with other PKS isoforms in the collection. Although KAF5 also showed strong expression, we only obtained a partial sequence for this isoform. Putative silenced transformants were screened by PCR for presence of the hygromycin resistance gene (hptII) and pSD-MFPKS12. Single-spore isolates of five transformants (LC2-6, -8, -11, -15, and -17) carried the hptII amplifier. MfPKS12 expression was further analyzed by qRT-PCR in pSD-MFPKS 12 transformants in culture. At 6 and 12 days of growth on PDA and V8 agar, only transformant LC2-17 had markedly reduced expression of MfPKS12 compared with Mf13-81. In the other transformants, MfPKS12 transcript levels were similar to those of Mf13-81 (Fig. 6).

The color of LC2-17 colonies appeared lighter than WT on PDA and SMM (Supplementary Fig. S9). Although melanin accumulated in LC2-17 mycelium, the levels were much less than in the WT mycelium or the other LC-2 transformants (Fig. 7). To determine if M. fructicola spore and appressorium turgor is affected by melanin accumulation, spore germlings were treated with PEG8000. Spores and appressoria of LC2-17 collapsed in the presence of 30\% PEG,
$254 \mathrm{~nm}$

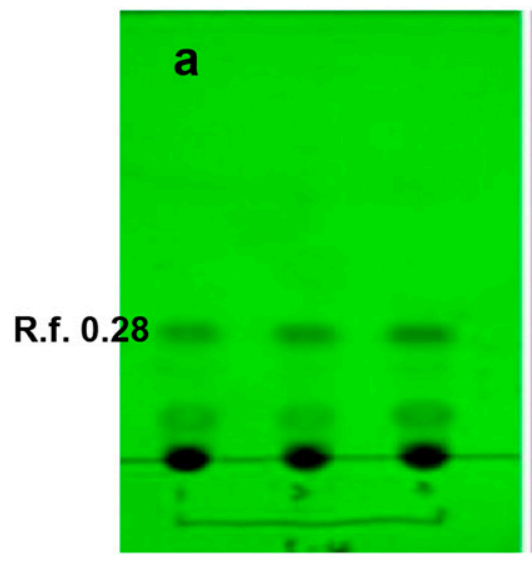

$365 \mathrm{~nm}$

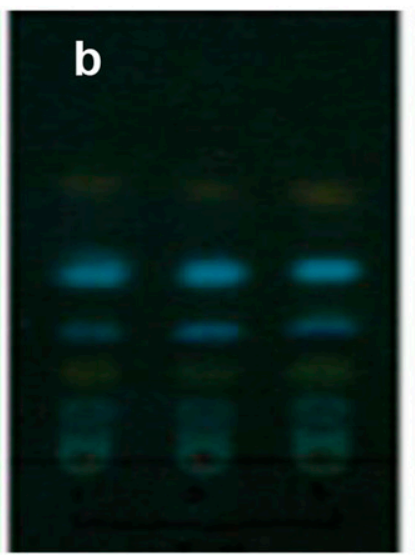

Bioassay

\section{$\mathrm{FeCl}_{3} / 365 \mathrm{~nm} \quad$ P. digitatum B. cinerea}

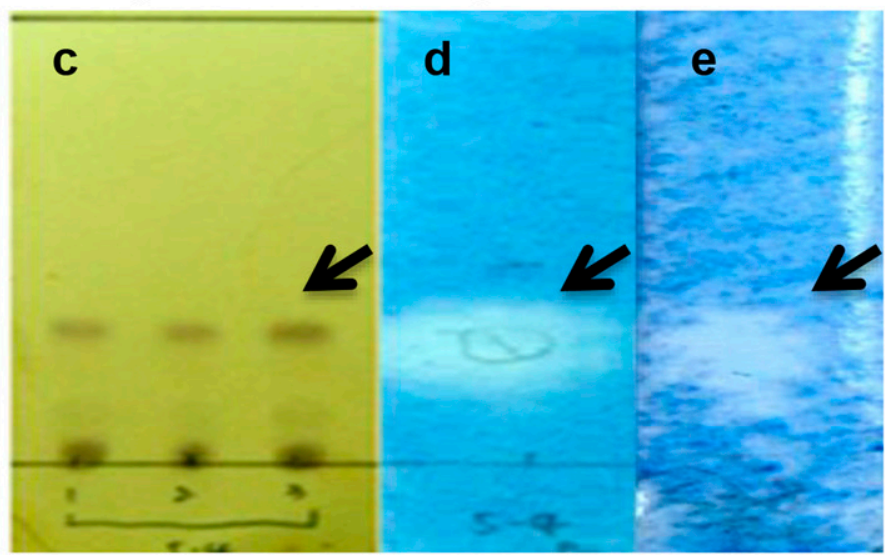

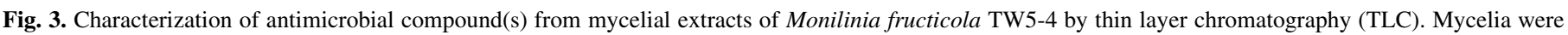

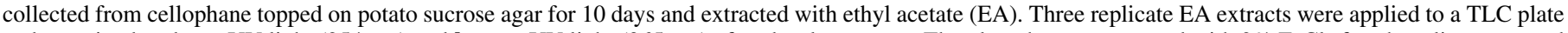

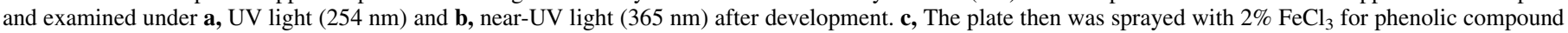

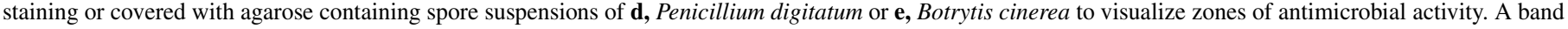
( $\mathrm{Rf}=0.28$, indicated with arrows) that stained with $2 \% \mathrm{FeCl}_{3}$ showed antimicrobial activity. 
while LC2-15 showed deformation in the presence of 35\% PEG (Fig. 8). However, spore/appressorial structures of Mf13-81 and transformants LC2-6 and LC2-8, which had WT melanin levels, maintained turgor and shape up to $35 \%$ PEG, but collapsed at $40 \%$ PEG (Fig. 8). No notable differences were observed in germination and appressorium formation between WT and the LC2 transformants. In addition, LC2-17 displayed similar growth and sporulation in culture to WT (Supplementary Fig. S10). However,
LC2-17 was less virulent on nectarine and peach fruit compared with Mf13-81 (Table 3).

\section{DISCUSSION}

In this study, we describe a $M$. fructicola strain, TW5-4, that displays strong antimicrobial activity, weak growth, and low virulence, but accumulates high levels of melanin. We determined

\section{A}

MF-1: chloromonilicin ESI-MS: $351[\mathrm{M}+\mathrm{H}]^{+}$ $373[\mathrm{M}+\mathrm{Na}]^{+}$<smiles>CC(=O)C1OC(=O)C=C(Cl)c2oc3cc(C)cc(O)c3c(=O)c21</smiles>
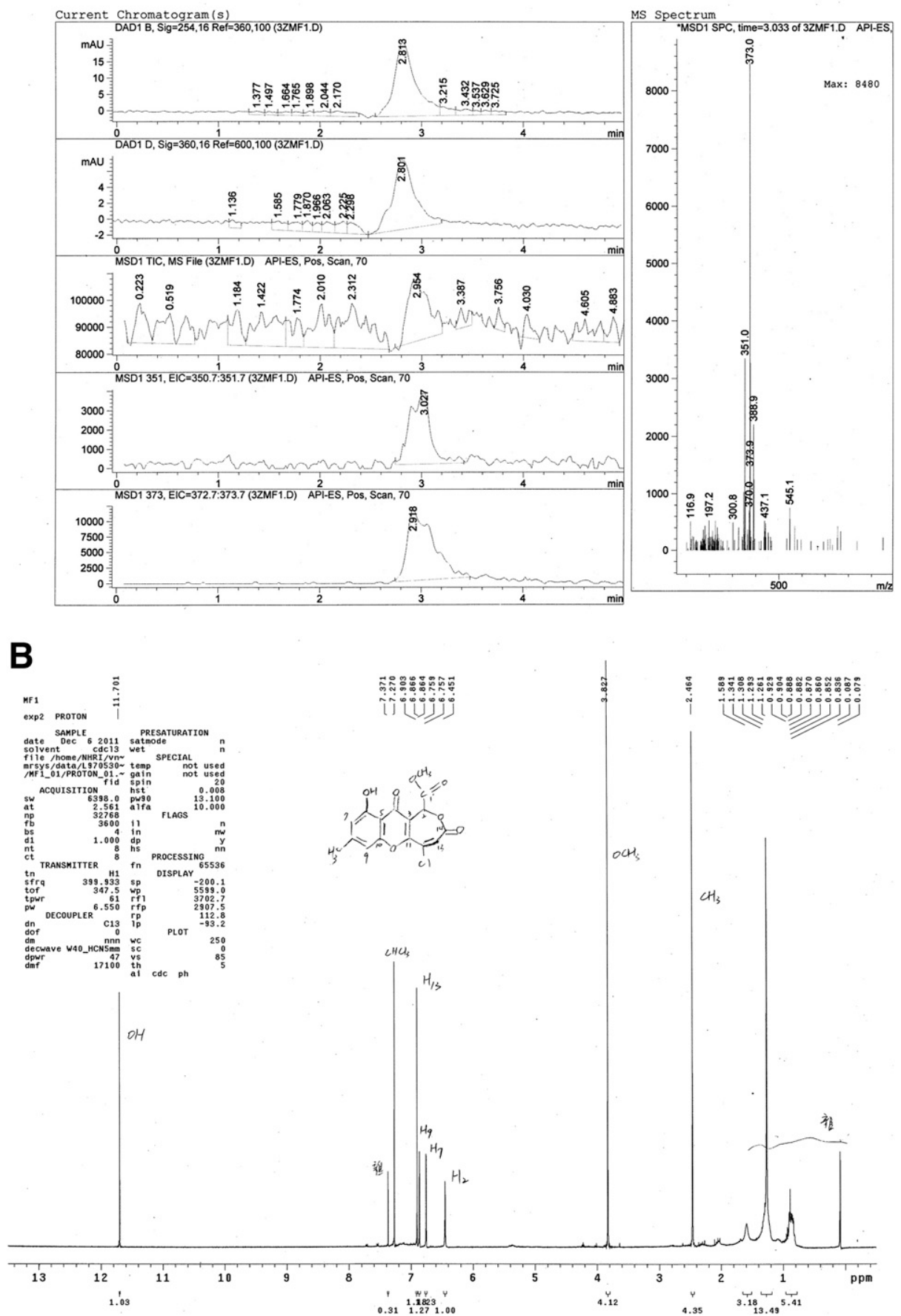

Fig. 4. High-resolution electro-spray ionization mass spectrometry (HRESIMS) and proton nuclear magnetic resonance $\left({ }^{1} \mathrm{H}\right.$ NMR) spectra for the purified chloromonilicin. A, Chloromonilicin structure and HRESIMS profile; and $\mathbf{B},{ }^{1} \mathrm{H}$ NMR profile. 
that the secreted antibiotic is the polyketide, chloromonilicin, first reported from benomyl-resistant $M$. fructicola strains isolated from cherry fruits (Sassa et al. 1985). In Taiwan, M. fructicola is widely distributed in peach orchards at elevations between 400 to $2000 \mathrm{~m}$. During screening of potential biocontrol microorganisms to inhibit growth of M. fructicola, we discovered Monilinia isolates able to inhibit the growth of various Trichoderma-like fungi. TW5-4 is one of these isolates that expresses strong antibiosis toward other fungal plant pathogens as well. In addition, TW5-4 inhibits WT isolates of $M$. fructicola, and grows very slowly compared with strains expressing low antimicrobial activity, suggesting self-inhibition. The principal antimicrobial compound detected by the OCIA using Penicillium as the indicator was chloromonilicin. Chloromonilicin and the related phenolic polyketides monilidiol, dechloromonilidiol, and bromomonilicin were shown to inhibit bacterial and fungal human pathogens, including Candida albicans and Trichophyton sp. (Kachi and Sassa 1986; Sassa et al. 1983). Monilidiol was reported to be phytotoxic on cherry leaves and to inhibit Staphylococcus aureus, while bromomonilicin showed a similar antimicrobial spectrum as chloromonilicin. TW5-4 may also produce monilidiol, dechloromonilidiol, and bromomonilicin. However, these were not apparent by OCIA, perhaps overshadowed by the abundance of chloromonilicin, and were not pursued further.

A

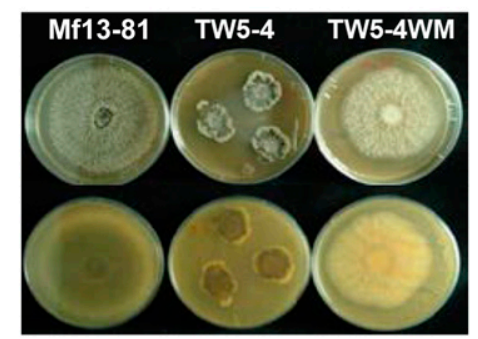

B
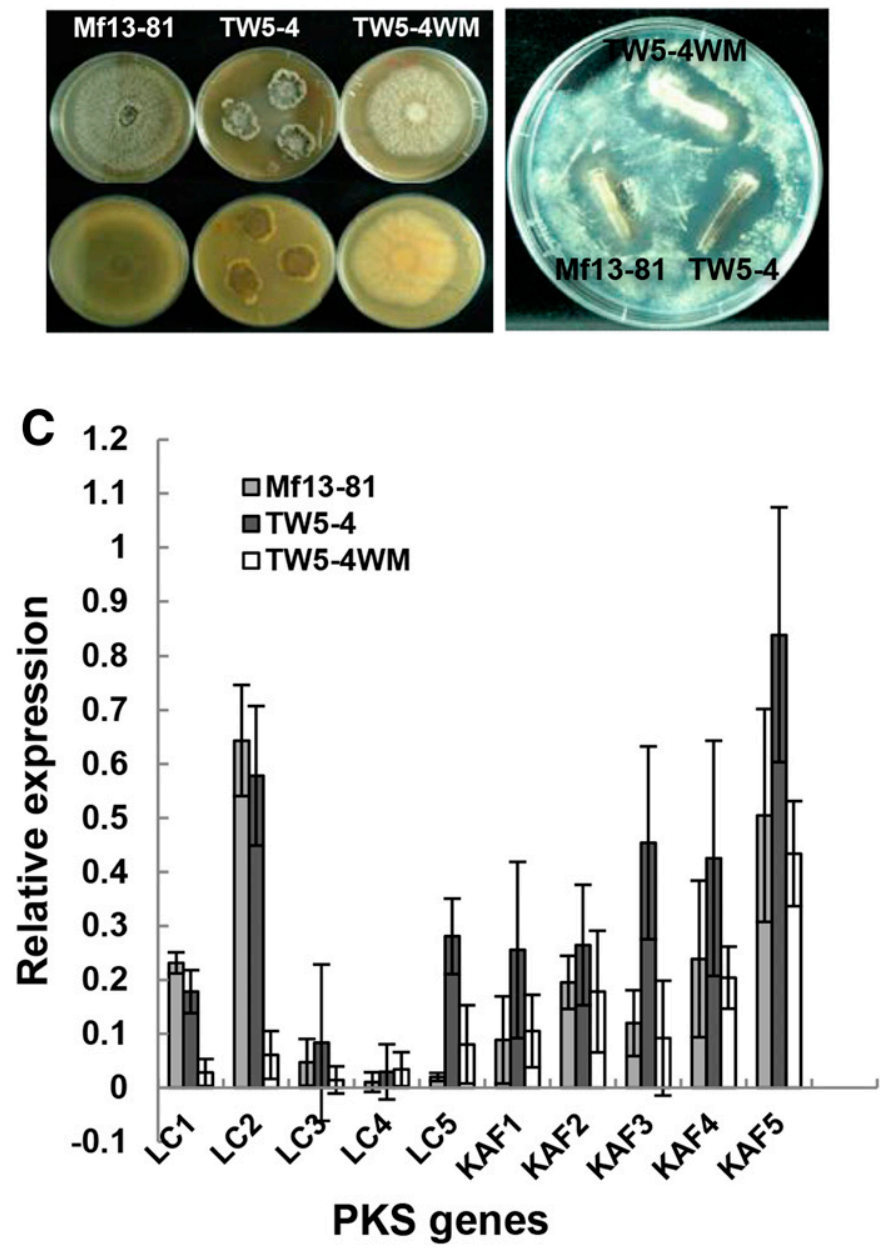

Fig. 5. Semiquantitative RT-PCR analysis of polyketide synthase (PKS) gene expression of Monilinia fructicola Mf13-81, TW5-4, and TW5-4WM on V8 agar, 6 days postinoculation. A, Colony morphology of the three strains; B, antimicrobial activity of the three strains against Penicillium digitatum DOB2; and $\mathbf{C}$, expression of PKS genes relative to the expression of the Tub2 gene in each strain. Means and standard errors from two independent experiments are presented.
Compared with Mf13-81 and the spontaneous albino mutant, TW5-4WM, TW5-4 displays reduced growth (Supplementary Fig. S2), sporulation, germination, appressorium formation (Table 2), and virulence (Supplementary Fig. S3), while overproducing both melanin (Supplementary Fig. S4) and chloromonilicin (Figs. 2, 3, and 4). Appressoria are important virulence factors in M. fructicola (Lee and Bostock 2006b), and the reduced appressorium formation observed with TW5-4 may contribute to its low virulence. Melanin is a virulence factor in many pathogenic fungi (Butler and Day 1998; Ludwig et al. 2014; Schumacher 2016). The lower virulence of TW5-4WM compared with Mf13-81 is consistent with its low melanin content. Chloromonilicin and DHN-melanin may share the same PKS at their biosynthetic initiation. Misregulation at this early step may explain the overproduction of chloromonilicin and DHNmelanin observed in the TW5-4 mutant. Although we demonstrated
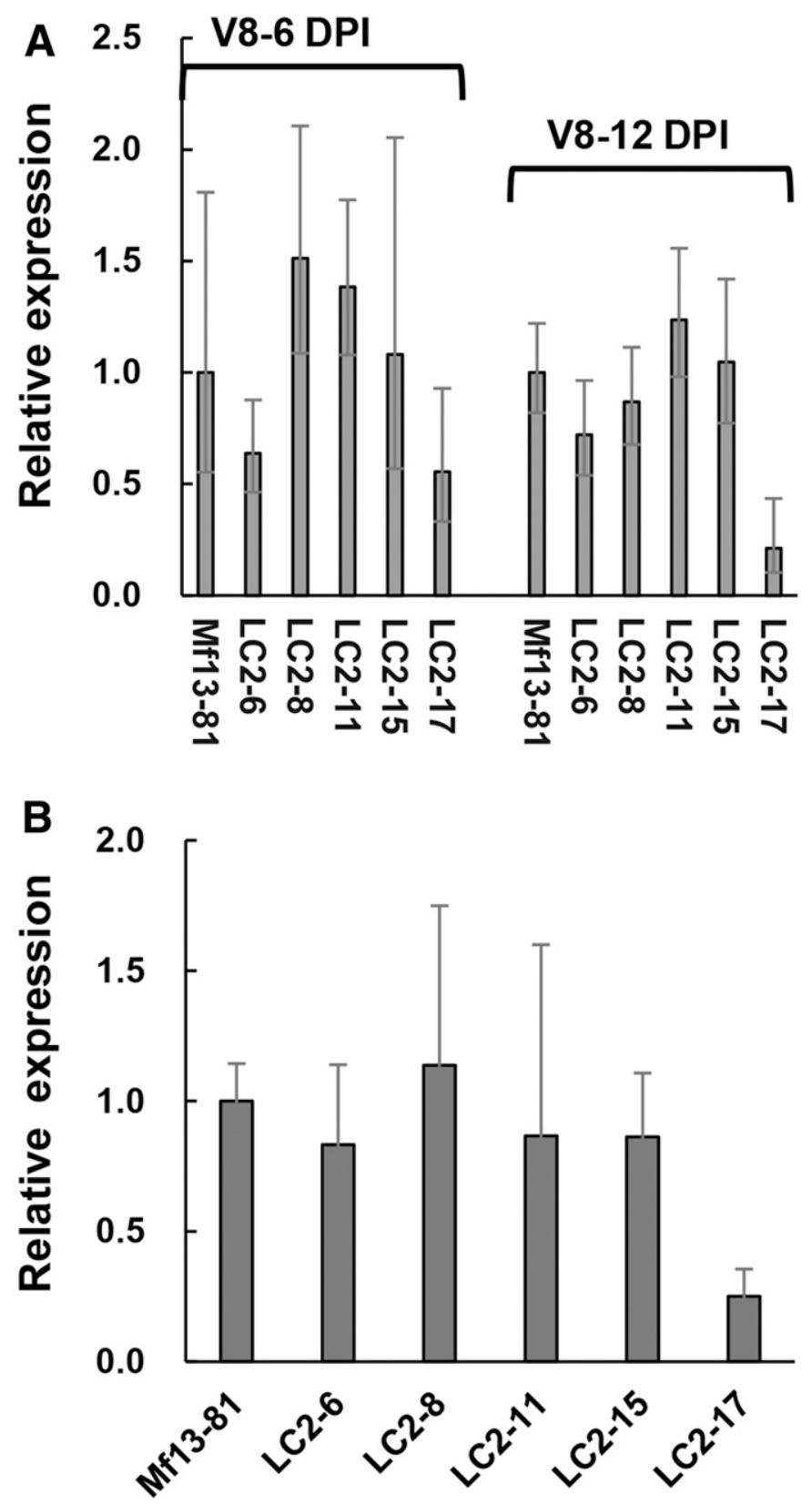

Fig. 6. Semiquantitative RT-PCR analysis for relative gene expression of Monilinia fructicola transformants carrying an MfPKS12 gene-silencing construct (LC2-6, -8, -11, -15, and -17) on A, V8 agar medium 6 and 12 days postinoculation (DPI), and B, PDA medium 12 DPI. Means and standard errors from two independent experiments are presented. 
phytotoxicity of mycelial extracts of TW5-4 on rose petals, the concentrations applied were high and bring into question the physiological relevance in the plant-microbe interaction of the phytotoxic material.

PKS genes are abundant in many pathogenic fungi, such as the family of 16 PKS genes in B. cinerea, 22 in Magnaporthe oryzae, and 11 to 24 in various Fusarium spp. (Amselem et al. 2011; Hansen et al. 2015). Genomes of several Monilinia species have been sequenced, and annotation of the $M$. fructigena genome has recently become available in the NCBI database (Landi et al. 2018; Naranjo-

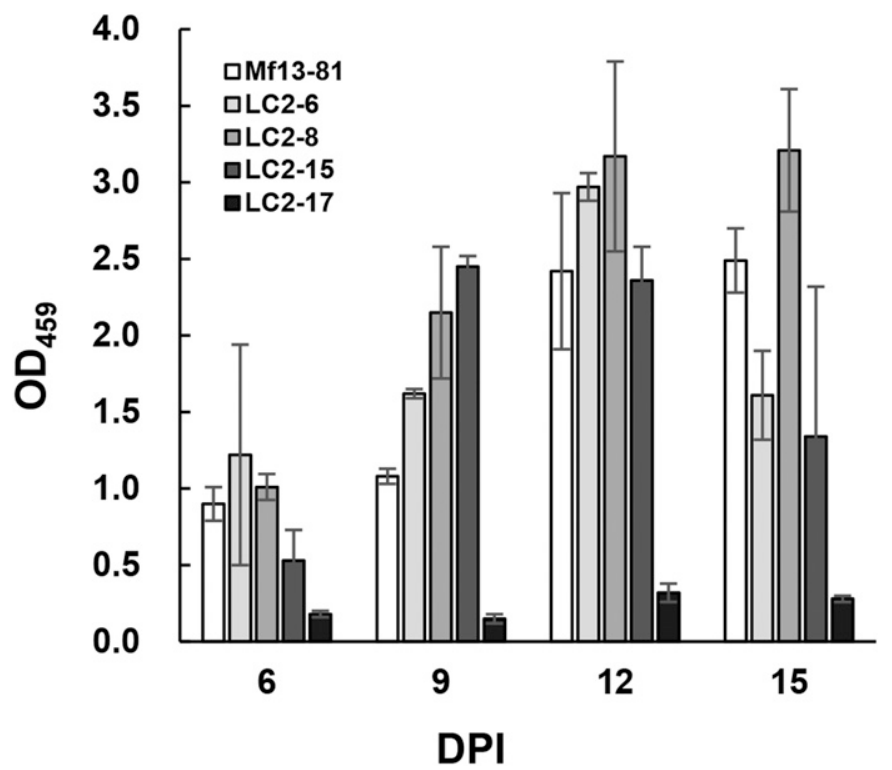

Fig. 7. Melanin accumulation of Monilinia fructicola transformants carrying an MfPKS12 gene-silencing construct (LC2-6, -8, -15, and -17) and the wildtype Mf13-81. Melanin was extracted from $100 \mathrm{mg}$ of mycelia on potato dextrose agar topped with cellophane at $6,9,12$, and 15 postinoculation days (DPI) and quantified by a spectrophotometry at $459 \mathrm{~nm}$.
Ortíz et al. 2018; Riveraet et al. 2018). Ten PKS proteins are encoded in the $M$. fructigena genome based on searching the NCBI database with "Monilinia polyketide synthase" as key words. Using degenerate and inverse PCR, we identified 10 PKS genes in the Mf13-81 strain of M. fructicola. However, it is possible that more than 10 PKS genes are present in the genomes of M. fructicola and other Monilinia species. Phylogenetic analysis based on amino acid alignments revealed that LC1 and LC2 (MfPKS12) are closely related to BcPKS13 and BcPKS12, respectively. Both BcPKS13 and BcPKS12 have been shown to be involved in DHN-melanin biosynthesis in B. cinerea (Schumacher 2016). LC3, LC4, and KAF2 are closely related to PKSs involved in biosynthesis of ACTtoxin and AF-toxin in Alternaria alternata and boticinic acid in B. cinerea (Dalmaiset et al. 2011; Meena et al. 2017).

$M f P K S 12$ expression is very high relative to other putative PKS genes in both Mf13-81 and TW5-4. The MfPKS12-silenced strain, LC2-17, had very low melanin content on PDA, consistent with a role for MfPKS12 in DHN-melanin biosynthesis in hyphae of $M$. fructicola. There was no difference in antimicrobial activity between LC2-17 and WT, suggesting that MfPKS12 is not involved in chloromonilicin biosynthesis. Nonetheless, LC2-17 was less

TABLE 3. Lesion sizes in nectarine and peach fruits inoculated with wild-type (WT) strain Mf13-81 of Monilinia fructicola and LC2 transformants carrying an MfPKS12 gene-silencing construct, $72 \mathrm{~h}$ postinoculation

\begin{tabular}{|c|c|c|c|c|c|c|}
\hline \multirow[b]{2}{*}{ Experiment } & \multirow[b]{2}{*}{ Fruit } & \multicolumn{5}{|c|}{ Lesion size $\left(\mathrm{cm}^{2}\right)$} \\
\hline & & WT & Means & Transformant & Ave & $\begin{array}{c}P \\
\text { value }^{\mathrm{a}}\end{array}$ \\
\hline \multirow[t]{3}{*}{1} & Nectarine & Mf13-81 & 4.5 & LC2-6 & 4.0 & 0.13 \\
\hline & cultivar & Mf13-81 & 4.1 & LC2-11 & 3.7 & 0.12 \\
\hline & Fantasy & Mf13-81 & 4.6 & LC2-15 & 3.3 & 0.02 \\
\hline \multirow[t]{3}{*}{2} & Nectarine & Mf13-81 & 4.3 & LC2-17 & 3.0 & $<0.01$ \\
\hline & cultivar & Mf13-81 & 2.7 & LC2-6 & 2.3 & 0.25 \\
\hline & Fantasy & Mf13-81 & 3.0 & LC2-15 & 2.0 & 0.07 \\
\hline \multirow[t]{3}{*}{3} & Peach & Mf13-81 & 3.9 & LC2-17 & 2.5 & $<0.01$ \\
\hline & cultivar & Mf13-81 & 0.9 & LC2-11 & 1.3 & 0.15 \\
\hline & Tian Tao & Mf13-81 & 1.7 & LC2-17 & 0.2 & 0.01 \\
\hline
\end{tabular}

a Reported $P$ values are based on a paired $t$ test.

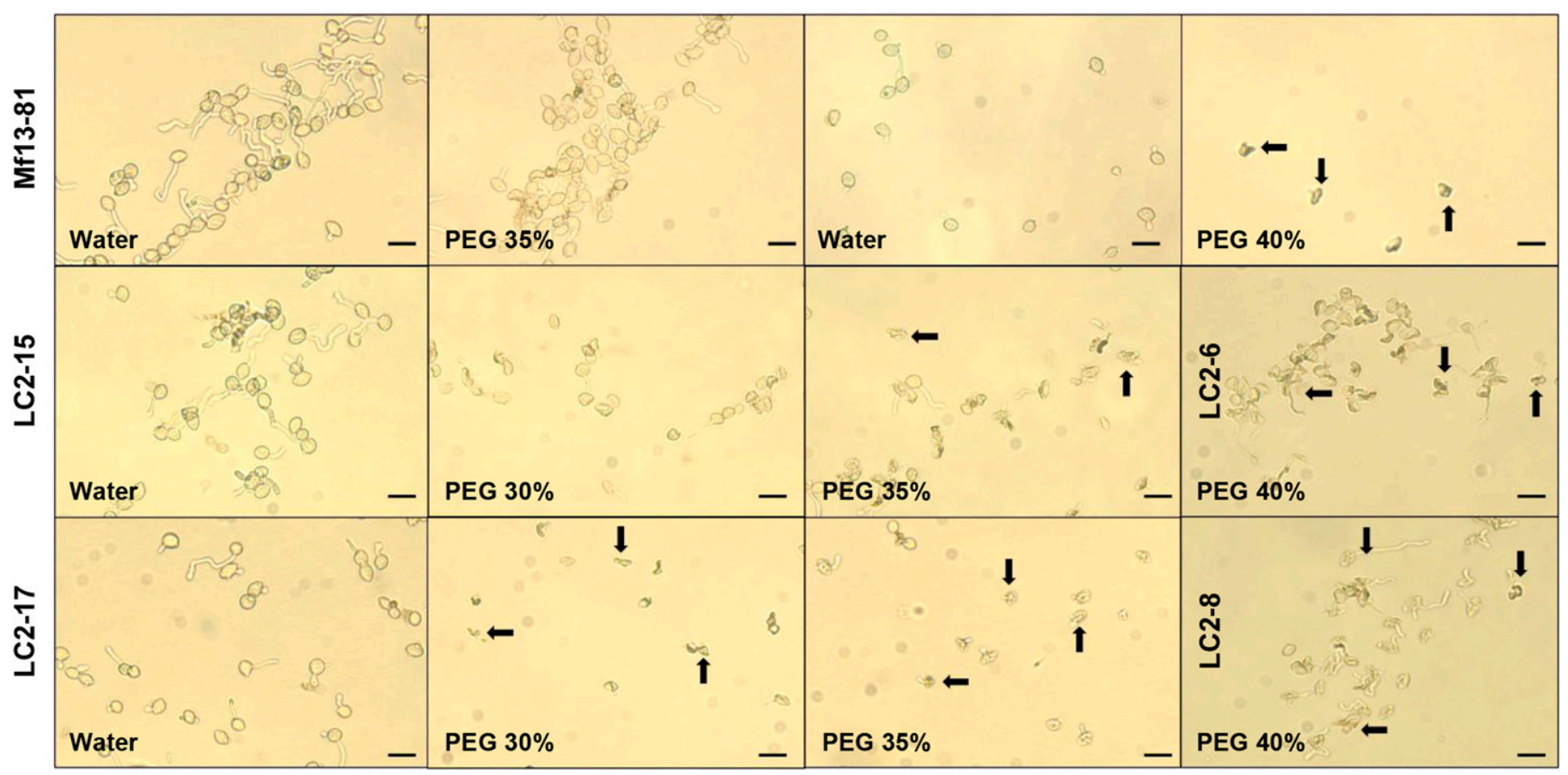

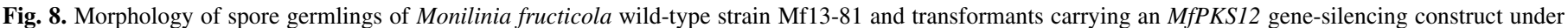
water or varying concentrations of PEG8000. Collapsed cells are indicated with arrows. Bar in each panel indicates $10 \mu \mathrm{m}$. 
virulent than WT in disease assays. Melanin contributes to environmental stress tolerance and survival of fungi (Fujii 2010). In our study, hypertonic PEG treatment collapsed and deformed spores and appressoria of $M$. fructicola. However, cells of the WT strain maintained form and function in the presence of higher PEG concentrations than the melanin-deficient LC-2 strains, consistent with the role of DHN-melanin in classic studies of Magnaporthe oryzae appressoria (Howard and Ferrari 1989). It follows that MfPKS12, through its putative role in DHN-melanin synthesis, contributes to cell wall integrity and turgor adjustment in spores and appressoria.

$M$. fructicola continues to be one of the most important fungal pathogens affecting stone fruit production throughout the Americas, Africa, Asia, Oceania, and more recently, Europe. The recently published high-quality draft genome of this pathogen (De Miccolis Angelini et al. 2019) is a resource that will help further understanding of genes and molecules critical for pathogenesis as well as growth and survival during other stages of its disease/life cycle.

\section{LITERATURE CITED}

Akamatsu, H. O., Chilvers, M. I., Stewart, J. E., and Peever, T. L. 2010. Identification and function of a polyketide synthase gene responsible for 1,8-dihydroxynaphthalene-melanin pigment biosynthesis in Ascochyta rabiei. Curr. Genet. 56:349-360.

Amnuaykanjanasin, A., Punya, J., Paungmoung, P., Rungrod, A., Tachaleat, A., Pongpattanakitshote, S., Cheevadhanarak, S., and Tanticharoen, M. 2005. Diversity of type I polyketide synthase genes in the wood-decay fungus Xylaria sp. BCC 1067. FEMS Microbiol. Lett. 251:125-136.

Amselem, J., Cuomo, C. A., van Kan, J. A., Viaud, M., Benito, E. P., Couloux, A., et al. 2011. Genomic analysis of the necrotrophic fungal pathogens Sclerotinia sclerotiorum and Botrytis cinerea. PLoS Genet. 7:e1002230.

Babitskaya, V. G., Shcherba, V. V., Filimonova, T. V., and Grigorchuk, E. A. 2000. Melanin pigments from the fungi Paecilomyces variotii and Aspergillus carbonarius. Appl. Biochem. Microbiol. 36:128-133.

Baker, S. E., Kroken, S., Inderbitzin, P., Asvarak, T., Li, B. Y., Shi, L., Yoder, O. C., and Turgeon, B. G. 2006. Two polyketide synthase-encoding genes are required for biosynthesis of the polyketide virulence factor, T-toxin, by Cochliobolus heterostrophus. Mol. Plant-Microbe Interact. 19:139-149.

Bingle, L. E., Simpson, T. J., and Lazarus, C. M. 1999. Ketosynthase domain probes identify two subclasses of fungal polyketide synthase genes. Fungal Genet. Biol. 26:209-223.

Bostock, R. M., Wilcox, S. M., Wang, G., and Adaskaveg, J. E. 1999. Suppression of Monilinia fructicola cutinase production by peach fruit surface phenolic acids. Physiol. Mol. Plant Pathol. 54:37-50.

Butler, M. J., and Day, A. W. 1998. Fungal melanins: A review. Can. J. Microbiol. 44:1115-1136.

Byrde, R. J. W., and Willetts, H. J. 1977. The Brown Rot Fungi of Fruit-Their Biology and Control. Pergamon Press, New York.

Chan, Y. A., Podevels, A. M., Kevany, B. M., and Thomas, M. G. 2009. Biosynthesis of polyketide synthase extender units. Nat. Prod. Rep. 26: 90-114.

Chiu, C. M., You, B. J., Chou, C. M., Yu, P. L., Yu, F. Y., Pan, S. M., Bostock, R. M., Chung, K. R., and Lee, M. H. 2013. Redox status-mediated regulation of gene expression and virulence in the brown rot pathogen Monilinia fructicola. Plant Pathol. 62:809-819.

Choquer, M., Dekkers, K. L., Chen, H. Q., Cao, L., Ueng, P. P., Daub, M. E., and Chung, K. R. 2005. The CTB1 gene encoding a fungal polyketide synthase is required for cercosporin biosynthesis and fungal virulence of Cercospora nicotianae. Mol. Plant-Microbe Interact. 18:468-476.

Chou, C. M., Yu, F. Y., Yu, P. L., Ho, J. F., Bostock, R. M., Chung, K. R., Huang, J. W., and Lee, M. H. 2015. Expression of five endopolygalacturonase genes and demonstration that MfPGl overexpression diminishes virulence in the brown rot pathogen Monilinia fructicola. PLoS One 10: e0132012.

Cox, R. J. 2007. Polyketides, proteins and genes in fungi: Programmed nanomachines begin to reveal their secrets. Org. Biomol. Chem. 5:2010-2026.

Cox, R. J., and Simpson, T. J. 2009. Fungal type I polyketide synthases. Methods Enzymol. 459:49-78.

Cox, R. J., Skellam, E., and Williams, K. 2018. Biosynthesis of fungal polyketides. Pages 385-412 in: Physiology and Genetics. The Mycota. Vol. 15. T. Anke and A. Schüffler, eds. Springer, Cham.

Dalmais, B., Schumacher, J., Moraga, J., Le Pecheur, P., Tudzynski, B., Collado, I. G., and Viaud, M. 2011. The Botrytis cinerea phytotoxin botcinic acid requires two polyketide synthases for production and has a redundant role in virulence with botrydial. Mol. Plant Pathol. 12:564-579.
De Cal, A., Sandín-Espãna, P., Martinez, F., Egüen, B., Chiou, C. M., Lee, M. H., Melgarejoa, P., and Prusky, D. 2013. Role of gluconic acid and $\mathrm{pH}$ modulation in virulence of Monilinia fructicola on peach fruit. Postharvest Biol. Technol. 86:418-423.

De Miccolis Angelini, R. M., Romanazzi, G., Pollastro, S., Rotolo, C., Faretra, F., and Landi, L. 2019. New high-quality draft genome of the brown rot fungal pathogen Monilinia fructicola. Genome Biol. Evol. 11:2850-2855.

Exarchou, V., Nenadis, N., Tsimidou, M., Gerothanasis, I. P., Troganis, A., and Boskou, D. 2002. Antioxidant activities and phenolic composition of extracts from Greek oregano, Greek sage, and summer savory. J. Agric. Food Chem. 50:5294-5299.

Fujii, I. 2010. Functional analysis of fungal polyketide biosynthesis genes. J. Antibiot. (Tokyo) 63:207-218.

Funa, N., Awakawa, T., and Horinouchi, S. 2007. Pentaketide resorcylic acid synthesis by type III polyketide synthase from Neurospora crassa. J. Biol. Chem. 282:14476-14481.

Hansen, F. T., Gardiner, D. M., Lysøe, E., Fuertes, P. R., Tudzynski, B., Wiemann, P., Sondergaard, T. E., Giese, H., Brodersen, D. E., and Sørensen, J. L. 2015. An update to polyketide synthase and non-ribosomal synthetase genes and nomenclature in Fusarium. Fungal Genet. Biol. 75:20-29.

Howard, R. J., and Ferrari, M. A. 1989. Role of melanin in appressorium function. Exp. Mycol. 13:403-418.

Hussain, H., Al-Sadi, A., Schulz, B., Steinert, M., Khan, A., Green, I., and Ahmed, I. 2017. A fruitful decade for fungal polyketides from 2007 to 2016: Antimicrobial activity, chemotaxonomy and chemodiversity. Future Med. Chem. 9:1631-1648.

Kachi, H., and Sassa, T. 1986. Isolation of moniliphenone, a key intermediate in xanthone biosynthesis from Monilinia fructicola. Agric. Biol. Chem. 50: 1669-1671.

Kawamura, C., Moriwaki, J., Kimura, N., Fujita, Y., Fuji, S., Hirano, T., Koizumi, S., and Tsuge, T. 1997. The melanin biosynthesis genes of Alternaria alternata can restore pathogenicity of the melanin-deficient mutants of Magnaporthe grisea. Mol. Plant-Microbe Interact. 10:446-453.

Kawamura, C., Tsujimoto, T., and Tsuge, T. 1999. Targeted disruption of a melanin biosynthesis gene affects conidial development and UV tolerance in the Japanese pear pathotype of Alternaria alternata. Mol. Plant-Microbe Interact. 12:59-63.

Kroken, S., Glass, N. L., Taylor, J. W., Yoder, O. C., and Turgeon, B. G. 2003. Phylogenomic analysis of type I polyketide synthase genes in pathogenic and saprobic ascomycetes. Proc. Natl. Acad. Sci. USA 100:15670-15675.

Laluk, K., and Mengiste, T. 2010. Necrotroph attacks on plants: Wanton destruction or covert extortion? Arabidopsis Book 8: $\mathrm{e} 0136$.

Landi, L., De Miccolis Angelini, R. M., Pollastro, S., Abate, D., Faretra, F., and Romanazzi, G. 2018. Genome sequence of the brown rot fungal pathogen Monilinia fructigena. BMC Res. Notes 11:758.

Lee, M. H., and Bostock, R. M. 2006a. Agrobacterium T-DNA-mediated integration and gene replacement in the brown rot pathogen Monilinia fructicola. Curr. Genet. 49:309-322.

Lee, M. H., and Bostock, R. M. 2006b. Induction, regulation, and role in pathogenesis of appressoria in Monilinia fructicola. Phytopathology 96: 1072-1080.

Lee, M. H., and Bostock, R. M. 2007. Fruit exocarp phenols in relation to quiescence and development of Monilinia fructicola infections in Prunus: A role for cellular redox. Phytopathology 97:269-277.

Lee, M. H., Chiu, C. M., Roubtsova, T., Chou, C. M., and Bostock, R. M. 2010. Overexpression of a redox-regulated cutinase gene, MfCUT1, increases virulence of the brown rot pathogen Monilinia fructicola on Prunus spp. Mol. Plant-Microbe Interact. 23:176-186.

Ludwig, N., Loehrer, M., Hempel, M., Mathea, S., Schliebner, I., Menzel, M., Kiesow, A., Schaffrath, U., Deising, H. B., and Horbach, R. 2014. Melanin is not required for turgor generation but enhances cell-wall rigidity in appressoria of the corn pathogen Colletotrichum graminicola. Mol. PlantMicrobe Interact. 27:315-327.

Meena, M., Gupta, S. K., Swapnil, P., Zehra, A., Dubey, M. K., and Upadhyay, R. S. 2017. Alternaria toxins: Potential virulence factors and genes related to pathogenesis. Front. Microbiol. 8:1451.

Mirocha, C. J., Wilson, E. E., and DeVay, J. E. 1961. Role of fumaric acid in hull rot disease of almond. Phytopathology 51:851-860.

Moriwaki, A., Kihara, J., Kobayashi, T., Tokunaga, T., Arase, S., and Honda, Y. 2004. Insertional mutagenesis and characterization of a polyketide synthase gene (PKS1) required for melanin biosynthesis in Bipolaris ory$z a e$. FEMS Microbiol. Lett. 238:1-8.

Naranjo-Ortíz, M. A., Rodríguez-Píres, S., Torres, R., De Cal, A., Usall, J., and Gabaldón, T. 2018. Genome sequence of the brown rot fungal pathogen Monilinia laxa. Genome Announc. 6:e0214-e0218.

Nguyen, Q. B., Kadotani, N., Kasahara, S., Tosa, Y., Mayama, S., and Nakayashiki, H. 2008. Systematic functional analysis of calcium-signaling proteins in the genome of the rice-blast fungus, Magnaporthe oryzae, using a high-throughput RNA-silencing system. Mol. Microbiol. 68:1348-1365. 
Nicholson, T. P., Rudd, B. A., Dawson, M., Lazarus, C. M., Simpson, T. J., and Cox, R. J. 2001. Design and utility of oligonucleotide gene probes for fungal polyketide synthases. Chem. Biol. 8:157-178.

Pusztahelyi, T., Holb, I. J., and Pócsi, I. 2016. Plant-fungal interactions: Special secondary metabolites of the biotrophic, necrotrophic, and other specific interactions. Fungal Metabolites. Reference Series in Phytochemistry. J. M. Mérillon and K. Ramawat, eds. Springer, Cham.

Rivera, Y., Zeller, K., Srivastava, S., Sutherland, J., Galvez, M., Nakhla, M., Poniatowska, A., Schnabel, G., Sundin, G., and Abad, Z. G. 2018. Draft genome resources for the phytopathogenic fungi Monilinia fructicola, $M$. fructigena, $M$. polystroma, and $M$. laxa, the causal agents of brown rot. Phytopathology 108:1141-1142.

Ryder, L. R., and Talbot, N. J. 2015. Regulation of appressorium development in pathogenic fungi. Curr. Opin. Plant Biol. 26:8-13.

Sassa, T., Horiguchi, K., and Suzuki, Y. 1989. Chloromonilicin acids A and B, novel catabolites of the growth self-inhibitor chloromonilicin isolated from Monilinia fructicola. Agric. Biol. Chem. 53:1337-1341.

Sassa, T., Kachi, H., Nukina, M., and Suzuki, Y. 1985. Chloromonilicin, a new antifungal metabolite produced by Monilinia fructicola. J. Antibiot. (Tokyo) 38:439-441

Sassa, T., Nukina, M., Sugiyama, T., and Yamashita, K. 1983. Monilidiols, characteristic and bioactive metabolites of benomyl-resistant strains of Monilinia fructicola. Agric. Biol. Chem. 47:449-451.
Schumacher, J. 2016. DHN melanin biosynthesis in the plant pathogenic fungus Botrytis cinerea is based on two developmentally regulated key enzyme (PKS)-encoding genes. Mol. Microbiol. 99:729-748.

Seshime, Y., Juvvadi, P. R., Fujii, I., and Kitamoto, K. 2005. Discovery of a novel superfamily of type III polyketide synthases in Aspergillus oryzae. Biochem. Biophys. Res. Commun. 331:253-260.

Seshime, Y., Juvvadi, P. R., Kitamoto, K., Ebizuka, Y., and Fujii, I. 2010a. Identification of csypyrone $\mathrm{B} 1$ as the novel product of Aspergillus oryzae type III polyketide synthase CsyB. Bioorg. Med. Chem. 18:4542-4546.

Seshime, Y., Juvvadi, P. R., Kitamoto, K., Ebizuka, Y., Nonaka, T., and Fujii, I. 2010b. Aspergillus oryzae type III polyketide synthase CsyA is involved in the biosynthesis of 3,5-dihydroxybenzoic acid. Bioorg. Med. Chem. Lett. 20:4785-4788.

Takano, Y., Kubo, Y., Shimizu, K., Mise, K., Okuno, T., and Furusawa, I. 1995. Structural analysis of PKS1, a polyketide synthase gene involved in melanin biosynthesis in Colletotrichum lagenarium. Mol. Gen. Genet. 249:162-167.

Teichert, I., and Nowrousian, M. 2011. Evolution of genes for secondary metabolism in fungi. Pages 231-255 in: Evolution of Fungi and Fungal-Like Organisms, The Mycota XIV. S. Pöggeler and J. Wöstemeyer, eds. Springer-Verlag, Berlin, Heidelberg.

Yu, P. L., Wang, C. L., Chen, P. Y., and Lee, M. H. 2017. YAP1 homologuemediated redox sensing is crucial for a successful infection by Monilinia fructicola. Mol. Plant Pathol. 18:783-797. 